\title{
La anticooperación internacional y el retorno de las políticas de poder
}

En 1973 Charles W. Yost, uno de los más destacados diplomáticos de Estados Unidos en la postguerra y Embajador ante Naciones Unidas durante la administración del Presidente Johnson, en una entrevista publicada por el "New York Times" estampó estos conceptos:

"Cuando Franklin Delano Roosevelt y Cordell Hull colaboraron en la organización de las Naciones Unidas, tenían la firme convicción de que el antiguo sistema de 'equilibrio de poderes' había sido incapaz de evitar las grandes guerras mundiales, sencillamente porque ningún país fuerte está conforme con un 'equilibrio' si éste no se 'inclina' en su favor; si no se siente un poco mejor armado, un poco más poderoso que sus rivales. $Y$ así el 'equilibrio de poderes' es una fórmula engañosa de competencia, intriga e inestabilidad, $y$ no de orden internacional, cooperación y paz...

El papel principal de las Naciones Unidas en esta estructura trilateral sería constituir el marco de las relaciones entre las grandes potencias y los dos tercios de la humanidad que viven en los países en desarrollo...".

Estas sabias conclusiones son las que tuvieron presente en 1945 los legisladores en la Gonferencia de San Francisco para crear un sistema de cooperación económica y social y de protección de los derechos fundamentales del ser humano que, bien aplicado, garantiza el mantenimiento de la paz y el progresivo mejoramiento de las condiciones de vida en las naciones de la periferia donde habitan los dos tercios de la población mundial.

Hago este recuerdo porque desde hace algunos años ha surgido

*El autor ha publicado recientemente "Cooperar o Perecer: El Dilema de la Comunidad Mundial", en grupo Editor Latinoamericano, para el Programa RIAL, Buenos Aires, 1965. 
una fuerte tendencia a revivir las políticas que el Embajador Yost, con gran sabiduría, aconsejaba evitar. En verdad esa tendencia nació con Henry Kissinger durante el gobierno de Nixon. Sin embargo, desde la elección del Presidente Reagan el proceso se ha acelerado. Han surgido sectores ultra conservadores que han adquirido gran peso en la competencia de grupos de poder para obtener decisiones gubernamentales que caracterizan a la gran democracia del Norte. Esos sectores van mucho más allá; prohíjan las políticas de poder dándole un tinte de aislacionismo hegemónico y para llegar a sus metas han emprendido un persistente y bien organizado trabajo de demolición del sistema de Naciones Unidas el cual, basado en principios de igualad jurídica, autodeterminación, no intervención, y solidaridad y cooperación, constituye un obstáculo muy fuerte para el triunfo de esas ambiciones. Naturalmente, la desaparición de la cooperación internacional organizada $y$ democrática permitiría un dominio polftico y económico aún más vasto y más fuerte que en la actualidad.

Uno de los elementos destacados de este movimiento anticooperación internacional es el grupo más conservador de la bancada republicana del Senado de Estados Unidos, cuyo apoyo necesita el Poder Ejecutivo. En aquel sobresale el Senador Jesse Helms, quien preside la Comisión de Agricultura. El otro elemento, tal vez el más peligroso, es la Fundación Heritage, que premunida de recursos que parecen inagotables ha desatado desde hace tres años una campaña de desprestigio contra las organizaciones del sistema de Naciones Unidas que llega a todos los continentes. Periódicamente publica "estudios" sobre cada una de estas instituciones que están plagados de inexactitudes, prejuicios, ignorancia y ausencia total de equidad; omitiendo, por cierto, las realizaciones positivas. De dichos estudios nacen una multitud de artículos que inundan los periódicos de docenas de países, sobre todo los de Estados Unidos. El objetivo es convencer a las opiniones públicas que esas organizaciones de cooperación son enemigas de esta nación, están manipuladas por el comunismo y derrochan el dinero que aportan los contribuyentes de los países más ricos. El votar en forma diferente a la de Estados Unidos sobre cualquier problema no sólo político sino que económico y social, lo consideran un ataque deliberado al propio país. Más aún, se ha dado el caso de que la señora Jane Kirkpatrick, Embajadora ante Naciones Unidas y muy ligada a Ia Fundación Heritage, al testimoniar ante el Senado que debatía el eventual retiro de esa nación de la UNESco incluyó entre una lista de cargos que presentó en contra del Director General de esa organización, Amadou Mahtar M'Bow, el hecho de que era "tercermundista". Esto quiere decir que si una organización cuyo objetivo según la Carta de las Naciones Unidas y su propia Constitución, es orientar la cooperación internacional para suprimir la miseria, el 
desempleo y la ignorancia cumple con dicho deber, ello constituye para la Embajadora de Estados Unidos ante las Naciones Unidas un atentado contra su país y justifica que éste le quite su apoyo.

La campaña de estos grupos ya les ha dado dividendos. El gobierno de Estados Unidos anunció hace poco menos de un año su retiro de la UNEsco y lo acaba de ratificar, haciéndose efectivo el 19 de enero de 1985, a pesar de que muchos países han manifestado que lamentan esta medida; que los círculos intelectuales y académicos de esa nación se han opuesto firmemente a ella; y que con la participación de representantes nortẹamericanos se han aprobado en la UNESGO modificaciones de las prácticas administrativas y politicas.

Por otra parte, meses atrás Holanda decidió imitar a Estados Unidos, lo que mucho ha sorprendido, por tratarse de una nación tradicionalmente favorable a Naciones Unidas.

En días pasados dos nuevos hechos han venido a confirmar lo que expresé más arriba acerca de los verdaderos objetivos de estas campañas. Cables recientes nos dan cuenta de que el gobierno de la señora Thatcher - a pesar de la opinión contraria de sus asociados en la Comuridad Económica Europea- anunció también su retiro de la UNESCO. Al mismo tiempo nos informan que el Presidente Reagan, después de reunirse con los líderes republicanos del Gongreso con la finalidad de discutir las economias necesarias para reducir el gigantesco deficit fiscal (que fue ignorado antes de las elecciones), "habría elegido a la Organización de las Naciones. Unidas para la Agricultura y la Alimentación - FAO- entre las otras organizaciones internacionales para un eventual retiro". Ello, según la misma información, se debería a "su pesado aparato burocrático y a una cierta predisposición de aquella a influencias ideológicas, en contraste con los intereses de Estados Unidos".

Es interesante analizar en estos dos casos las razones aducidas por los gobiernos o por sus consejeros.

El argumento invocado por la "Dama de Hierro" que gobierna Gran Bretaña para abandonar la Organización de las Naciones Unidas para la Educación, la Ciencia y la Cultura, es que su país no recibe de ésta beneficios equivalentes al monto de su contribución anual. Aún aceptando este enfoque mercantilista de la nación que junto con Francia convocó en 1945 la Conferencia que creó la UNESGGO, el argumento sale muy mal parado si se examina lo que Gran Bretaña aporta a la Organización y lo que recibe de ella. Su contribución, que conforme con las reglas establecidas se calcula en base al Producto Nacional per cápita y a otros factores, 2lcanza a 
siete millones de dólares al año. Pero, desde el punto de vista de la balanza de pagos, Gran Bretaña obtiene mucho más de la UNEsco. Los-funcionarios británicos que trabajan en la Organización reciben anualmente alrededor de 21. millones de dólares y la UNESCO compra -en el mismo período- productos británicos por un valor de 17 millones de dólares.

El anuncio de un eventual retiro de FAO por parte de Estados Unidos se funda en razones aún más débiles que las que se esgrimen respecto a la uNESCO. Como esta vez no fue posible hablar de "excesiva politización" y de "tendencias comunizantes" porque la política -en el sentido que la entienden los detractores- no ha aparecido en FAO y tampoco en las grandes conferencias mundiales que organizó en los cinco años pasados, una sobre Reforma Agraria y Desarrollo Rural y otra sobre Pesca, se ha recurrido al pretexto que ya mencioné, el cual es de una vaguedad abismante: el de la supuesta "predisposición a influencias ideológicas contrarias a los intereses norteamericanos". ¿Cuáles son esas tendencias ideológicas? $\mathrm{Na}$ die las ha precisado. No puede pensarse en la influericia soviética, pues la URss no es ni ha sido nunca miembro de la FAO. ¿Acaso podría ser el empeño de FAO por mejorar la situación del campesino y por reformar las condiciones económicas, sociales y culturales de las áreas rurales de los países pobres y de este modo acelerar el desarrollo rural? Imposible, Estados Unidos fue el iniciador en Naciones Unidas de las políticas de reforma agraria, después de haberlas impuesto o impulsado en Japón, Corea del Sur y Taiwán. Tal vez algunos defensores de las políticas hegemónicas de poder consideren que las críticas que muchas delegaciones de países miembros de FAO han formulado acerca del uso de alimentos con fines meramente políticos constituyen un ataque ideológico contra Estados Unidos o que también lo es la insistente propuesta de FAO, desde su fundación, para que se apruebe un sisema mundial de seguridad alimentaria que permita acumular reservas capaces de detener catástrofes como las que están afectando a la región del Sahel y a Etiopía. Los intentos de FAO no han logrado el éxito esperado. Las grandes potencias con excedentes en granos quieren disponer de esos excedentes de modo discriminatorio, de acuerdo con sus intereses económicos y también políticos. $\mathrm{Y}$, a propósito de esas catástrofes, cabe señalar que el intento de retiro de FAO se anuncia en momentos muy poco oportunos, lo que coloca a sus promotores en situación poco airosa. Las circunstancias verdaderamente trágicas que afectan a una vasta región del Africa no es, por cierto, la oportunidad más apropiada para debilitar a la organización mundial fundada para ocuparse de estas cuestiones y que ha dado desde hace años altísima prioridad al drama africano. Desde la década pasada FAO ha utilizado todos los recursos a su alcance para atender las ne. 
cesidades del continente que muestra una mayor vulnerabilidad desde el punto de vista alimentario. Por un lado, su crecimiento demográfico sigue superando el aumento de la producción de alimentos. Por el otro, la región tan duramente afectada sufre los efectos de las politicas de la era colonial y las de las corporaciones transnacionales después de la independencia. La ruptura del equilibrio ecológico producido por la sustitución de los cultivos de productos alimenticios por los que son de exportación, ha disminuido la producción de alimentos para sus pueblos. La desertificación se ha extendido en un grado muy alto y las migraciones de los campesinos a las ciudades constituye un fenómeno alarmante. Ha condenado a los habitantes a procurar colmar sus déficit con importaciones o ayuda internacional, la cual no siempre llega.

$\mathrm{E} 1$ prestigio de la FAO es muy grande. Por eso anualmente recibe contribuciones voluntarias para ejecutar proyectos en el Tercer Mundo, en especial en Africa, de igual o mayor monto que los 200 millones de dólares que constituyen su presupuesto ordinario. Los 49 millones que aporta Estados Unidos de acuerdo a las disposiciones legales, representan una suma importante, aunque su monto poco influirá en el déficit fiscal de 210 mil millones de dólares. Este hecho no impedirá que la FAO continúe trabajando con igual empeño y mística, aunque más lentamente. Lo grave es que esta decisión vendría a acentuar la tendencia de prescindir completamente de las organizaciones del sistema de Naciones Unidas-salvo de aquellas que funcionan con voto ponderado-. Y, en todo caso, van creando desconfianza en las opiniones públicas mundiales.

Espero que la amenaza no prospere en esta ocasión. En especial considerando que fue el Ministro de Agricultura de Estados Unidos quien presidió la última Conferencia de FAO, aprobó su presupuesto y elogió su organización y sus obras. Además este país es el que mayor adelanto tecnológico ha alcanzado en el sector agrícola y no puede alejarse de una institución que necesita de su cooperación en este aspecto. Por otra parte, FAO es la organización que puede considerarse como hija directa de dicha nación, pues fue obra de la visión y decisión personal del Presidente Roosevelt en 1943, quien vio no sólo que habría que prepararse para socorrer las posibles hambrunas que causaría la guerra, sino también que era necesario enfrentar colectivamente un problema mundial producto del creciente aumento de la población en el planeta. Y su labor es de gran seriedad y devoción por los objetivos expuestos en su carta constitucional.

Corresponde a las naciones del Tercer Mundo encabezar la defensa contra la ofensiva anticooperación. Les va en ello el futuro de su desarrollo dentro de un marco que refuerce su propia identidad y una mayor independencia política y económica. Ellas han re- 
cibido ya golpes muy serios de parte de los países del Norte: como son las polfticas proteccionistas que afectan sus exportaciones y los intereses brutales que han incrementado desmesuradamente la deuda externa. Si se agrega a esto el intento de despojar a los paíess en desarrollo de las instituciones creadas para proteger sus intereses vitales, cabría interpretarlo como una verdadera declaración de guerra económica a los pueblos de la periferia. 